\title{
Physician Supply
}

\section{Mortality and Physician Supply: Does Region Hold the Key to the Paradox?}

\author{
Thomas C. Ricketts and George M. Holmes
}

Objective. To determine if the supply of physicians has a consistent relationship with mortality across regions.

Data Sources. County-level data describing the supply of physicians, mortality, and socioeconomic conditions of the population as provided in the Area Resource File (BHPr, HRSA) and the Compressed Mortality File (NCHS, CDC).

Study Design. Ordinary least squares and geographically weighted regression models with age-adjusted all-cause and disease-specific mortality as the dependent variables were specified using pooled data from 1996 to 2000 to test for the relationship with primary care and specialist physician-population ratios. The residuals from the OLS models were mapped and examined for potential clustering. A series of geographically weighted regression models were run for all 3,070 counties and the $z$-scores and significance of the models mapped.

Principal Findings. The association between primary care physician supply and mortality was not observed in contrast to other studies; mapping the residuals of those models suggested regional clustering. When weighted geographically, the relationship between primary care and specialist physician supply and mortality presents a mixed pattern. The results show strong regional patterns that may explain the lack of a consistent national association. Primary care physicians are associated with decreased mortality on the east coast and upper midwest, but that correlation disappears or is reversed in the west (with the exception of Washington State) and south central states. Conclusions. We find evidence that there are regionally focused association between physician supply and mortality, holding constant population characteristics that reflect the influence of social and economic characteristics. However, these relationships are not consistent across the United States; there are regions where there are stronger and weaker associations between type of practitioner and mortality and other regions where no association is apparent. This suggests that the direction for further analysis lies in the understanding of the regional differences and whether there are policy alternatives to address these different patterns.

Key Words. Primary care, geography, physician supply, mortality

Recently there has been a series of research reports that have described positive associations between the supply of primary care physicians and health 
outcomes (Shi 1992, 1994; Forrest and Starfield 1996; Shi et al. 2003a, b, 2005; Starfield et al. 2005; Starfield, Shi, and Macinko 2005). This favorable association of medical resources and health has not always been accepted. The contribution of medical resources to population health status has long sparked vigorous debate. Medical care, it has been argued, contributed little to the dramatic reduction in overall mortality rates in the twentieth century $(\mathrm{McKe}-$ own 1979). Analysis of long-term mortality trends in the United States from 1900 to 1973 found that medical care could account for very little of the overall decline in mortality (McKinlay and McKinlay 1977). Other studies found that the supply of physicians has been observed to have a "persistent but puzzling positive correlation" with mortality rates that could not be "adjusted away" by covariates such as income (Young 2001). An explanation was offered by Young (2001) that growing industrial cities "attract an oversupply of doctors and also attract rural immigrants whose health breaks down in the context of city life."

Other investigators have replied that this may be an artifact and that associating long-term mortality trends to physician supply did not reflect a lack of contribution by the medical profession, and that "such evidence is not to be interpreted to mean that medical care is not important, but rather it suggests that other factors have contributed to the decline in mortality" (Kindig 1997). Negative relationships (more physicians associated with lower mortality) have been reported for the United States for overall physician supply (Kindig, Seplaki, and Libby 2002) as well as for the supply of primary care physicians (Starfield et al. 2005). These analyses, with the exception of the work reported by Kindig, Seplaki, and Libby (2002), have generally accepted the applicability of the geographical units of analysis that are used to aggregate the indicator of medical resources and which provide the denominator for the mortality rate. These have included U.S. counties, cities and metropolitan areas, or nations. They have not considered regional effects or variations in the size of the denominator areas. This paper explores whether those geographical aspects of the units of analysis may contribute to the patterns of correlation of practitioner supply and mortality.

This study builds on a previously published work by Starfield et al. (2005), examining the relationship between mortality and primary and

Address correspondence to Thomas C. Ricketts, Ph.D., Sheps Center for Health Services Research, The University of North Carolina, 725 M.L. King, Jr. Blvd CB 7590, Chapel Hill, NC 27599-7590. George M. Holmes, Ph.D., is Vice-President of the North Carolina Institute of Medicine, Durham, NC. 
specialty physician supply, and attempts to replicate those results while controlling for the effects of geography. Examining pooled mortality data for U.S. counties from 1996 to 2000, that study found that U.S. counties with higher supply of primary care physicians have lower mortality; while counties with a higher supply of specialists generally have higher mortality. The earlier study suggested that any policies intended to improve health outcomes for underserved areas ought to concentrate on strengthening primary care resources and that this could be achieved at the local level.

One goal of this analysis is to determine if the effect is consistent across all regions of the United States and, when regional patterns are considered, whether that effect remains. We extend the analysis by accounting for possible specification problems, both statistical and geographical, that might lead to different conclusions and hence to different policies. If the earlier analysis holds, policy emphasis should be placed upon the strengthening of local primary care supply to meet effective minimum if not optimal levels. If there are regional effects, alternative policies may be better, including the support of regional systems and using both specialist and primary care supply standards for determining whether a community qualifies for governmental support.

\section{StUdy DATA AND METHODS}

Like the Starfield et al. study, the mortality data and physician supply data as well as covariates for the period 1996-2000 for our work were drawn primarily from the 2002 Area Resource File (ARF) distributed by the U.S. Bureau of Health Professions. The selection of the physician supply ratios used the same method as the earlier article including office-based, patient-care physicians in family medicine or general practice, internal medicine, and general pediatrics as primary care practitioners and, in this analysis, all other patient care, officebased practitioners were considered specialists. ${ }^{1}$

The Starfield et al. study of county-level mortality reported using a mixed, or random effects, regression model. ${ }^{2}$ An alternative is a fixed effects model that, for these data, we feel is preferred. The choice of a random versus fixed effects model can have important effects on the conclusions that can be drawn from data (Glance et al. 2006). A fixed effects model allows the covariates to be correlated with a county-level time-invariant unobserved effect. This is especially important with these data because there are multiple years of mortality and physician supply. It is reasonable to postulate that physician supply might be systematically lower in counties that tend to have higher 
historical mortality, reflecting many factors beyond physician supply itself that are not observed by the analyst. This time-invariant effect would tend to bias the results in a random effects model.

Most importantly, for this study, the Starfield et al. study, and related work did not include an explicit approach to account for the geographic nature of the data. There are reasons to suspect that mortality may be spatially correlated, as cartographic displays of mortality rates show very strong regional tendencies which are supported by spatial statistics (Pickle et al. 1996; Cossman et al. 2003; James et al. 2004). The absence of geographic analysis is not unusual, as most ecologic analyses do not account for spatial relationships across boundaries.

We generally use the same data sources, the ARF distributed by the Bureau of Health Professions, Health Resources and Services Administration, U.S. Department of Health and Human Services, and covariates as reported in Starfield et al. All estimations are performed using Stata ${ }^{\mathbb{B}}$ 9.1. We first show the results of the estimation using methods as close to the original analyses as possible, and then we explore variations that may cover some anomalies in the data. All estimation programs and data are available from the authors upon request.

\section{Random versus Fixed Effects Models}

Because the data are longitudinal in nature, it is natural to account for withincounty variation. The original study specifies what is commonly known as a "mixed" model. One restriction of this model is that the random county-specific intercept is assumed to be uncorrelated with the covariates in the model. This assumption is questionable in this application, as areas with high historic mortality (for reasons unobserved to the analyst) might have lower physician supply. Fortunately, there exist models that relax this assumption. One possible model is the fixed effects model, which allows the county-specific intercept to be correlated with covariates. ${ }^{3}$ Both models specify the general form

$$
M_{i t}=S_{i t} \alpha+X_{i t} \beta+\mu_{i}+\varepsilon_{i t}
$$

where $M$ is the mortality rate in county $i$ at time $t, S$ the provider supply (per 10,000 population), and $\alpha$ the parameter of interest-the effect of provider supply on mortality, $X_{i t}$ is a matrix of other characteristic for county $i$ at time $t, \mu_{i}$ is a time-invariant county component unobserved by the analyst, and $\varepsilon_{i t}$ is an idiosyncratic error. The central difference between the "random" effect model and the "fixed" effect model is the treatment of the $\mu_{i}$. The random effect model assumes that the $\mu_{i}$ is uncorrelated with the observed factorssimilar to the standard statistical assumption regarding the error in an ordinary 
least squares regression. The fixed effect model, however, relaxes this assumption and allows the $\mu_{i}$ to be correlated with the observed county characteristics. It can be shown (e.g., Wooldridge 2002) that the fixed effect model is equivalent to a regression of differences in means

$$
\left(M_{i t}-M_{i}^{*}\right)=\left(S_{i t}-S_{i}^{*}\right) \alpha+\left(X_{i t}-X_{i}^{*}\right) \beta+\varepsilon_{i t}
$$

Thus, deviations from a county's average physician supply identify the $\alpha$ parameter.

A Hausman and McFadden (1984) test can be used to support this assumption by comparing the coefficients of the random effects and fixed effects models. One consequence of fixed effects models is that the effect of each covariate is identified by changes within the county over time. Random effects models ask: "How does mortality in high physician supply areas compare to mortality in low physician supply areas?" Fixed effects models ask: "What happens to mortality in an individual county as the physician supply changes?" The latter is more relevant from the perspective of policy interventions that explicitly increase physician supply in communities. The former explores the existing relationship between practitioner supply and mortality.

\section{Spatial Effects}

One potentially important limitation of the earlier analysis is that it assumes that the effect of physician supply on mortality is constant for all counties across the country. There are many reasons this relationship might not hold. County size varies widely - the average county in Arizona is 36 times larger (in land area) than the average county in Rhode Island. The extent to which the county is a useful approximation of the market for primary care services may vary widely. Secondly, the relationship between primary care and mortality may vary regionally due to local practice patterns. Evidence suggests that physician practice patterns vary across the country (Goodman et al. 1996; Fisher and Wennberg 2003) and that there is significant variation in the supply of practitioners (Goodman et al. 2003) as well as the outcomes of care (Wennberg, Fisher, and Skinner 2004). The extent to which these practice patterns affect mortality will condition the effect of supply on mortality. Finally, individual care-seeking behavior may vary. The health of rural residents, for example, may be less sensitive to physician supply due to a different view of what is appropriate for medical intervention.

Regional and geographic patterns of the relationship between practitioner supply and mortality when controlled for population variations may be detected by mapping the error terms of a regression; patterns might emerge in 
the degree to which the model under or over predicts the outcome variable. This residual mapping was done in this analysis and a recognizably regional pattern emerged. There were apparent clusters of counties where the model closely predicted mortality as well as clusters where the data under and overpredicted. This suggested that some form of statistical geographic analysis would help identify the spatial relationship between physician supply and mortality.

One way to examine the geographic relationships of a series of variables with a dependent population-based rate as dependent variable in a multivariate model is to use geographically weighted regression (GWR). This technique performs a series of regressions-one for each small area unit, in this case counties-such that only "geographically relevant" counties are included in the regression. This meant the estimation of 3,070 separate regressions, one for each county in the United States (excluding Hawaii and the District of Columbia). The number of cases included for each county would depend on the number of counties falling within a relevant distance constraint, a function of the size of the counties and the distances between geographic centers. In effect, GWR makes use of the results of separate regressions for each county in the data set using a weighted value of the potential effects of the physician supply on all surrounding counties. In this analysis the effect was measured out to 450 miles. ${ }^{4}$ This approach allows the effect of physician supply (and all other covariates) to vary spatially with adjacent county supply weighted by distance. To illustrate, for a small county adjacent to another small county, there would be a strong proportional influence. For a large county adjacent to another large county, there would be a smaller effect, an even smaller effect for the very large counties of the Intermountain west. This would adjust for the variable effect of the distance between population centers but allow for some influence of out-of-county supply. For example, it may be the case that county-level physician supply is an important predictor in the small counties of the East (where counties may more accurately reflect the market and relevant geographic impact for primary care) but less important in large counties of the West where the county is too large to be reasonable proxy of the market for primary care.

\section{PRIMARY CARE AND Mortality, RePEATING PRIOR ANALYSES}

We begin by following the procedures reported by Starfield et al. (2005). Their data source was the 2002 ARF (Bureau of Health Professions 2002). Although 
the data for both studies were drawn from the same source, there were slight differences in the summary statistics for the covariates. For example, our value for percent African American is 9.06 percent in 1996; they report 9.17 percent in 1996. One possibility is that the summary statistics reported in the earlier published report may be based on a sample other than the study sample; that study lists included variables that are not available in the 2002 ARF. For example, the dependent variable is described as age-adjusted mortality (Starfield et al. 2005), but the $2002 \mathrm{ARF}$ does not contain the data to calculate this variable. ${ }^{5}$ The ARF does contain, however, the information necessary to compute the unadjusted (by age) mortality rate, and the means for these variables are similar. We computed age-adjusted mortality rates per 10,000 residents, using the Compressed Mortality Files from the National Center for Health Statistics, Centers for Disease Control and Prevention. The mortality rates are adjusted to the 2000 population. In the subsequent analysis we used both variants, but report here the results of the analysis of age- and genderadjusted morality rates, which better capture the nature of "population health" in the community.

For our analysis we used the active, nonfederal, office-based, patient care, primary care total reported for each county in the ARF for the primary care supply, and the ratio was computed using the single-year population also reported in that source in the ARF. In order to obtain these variables for all four specialties, we use the ARF files from 1998 to 2002 inclusive. We ran the models for both the age-adjusted and the raw mortality rates to compare the results with the Starfield et al.'s results (Table 1).

The results of this analysis are summarized in Table 2, which follows the format of Exhibit 2 in the original study (included as Appendix A).

These results differ from those presented by Starfield et al. who report five of the six primary care results negative (meaning lower mortality where there are more primary care physicians) and significant. Of the six specialist results, they report two positively related to mortality, four insignificant, and one negative. In our results, we find that counties with more primary care supply have higher all-cause mortality, or a positive association. The cancer mortalityprimary care-adjusted result reverses sign in our result and all three of the unadjusted specialist results change sign, implying that counties with more specialty supply have lower mortality with two regressions reaching significance. However, most of the statistical evidence occurs in unadjusted models, which may suffer from confounding bias. Reviewing only the six adjusted-mortality models, there is little evidence supporting a mortality decrease resulting from increase in physician supply-either primary care or specialty. 
Table 1: Summary Statistics for Variables

\begin{tabular}{|c|c|c|c|c|c|c|c|c|c|c|}
\hline \multirow[b]{2}{*}{ Variable } & \multicolumn{2}{|c|}{1996} & \multicolumn{2}{|c|}{1997} & \multicolumn{2}{|c|}{1998} & \multicolumn{2}{|c|}{1999} & \multicolumn{2}{|c|}{2000} \\
\hline & Mean & $S D$ & Mean & $S D$ & Mean & $S D$ & Mean & $S D$ & Mean & $S D$ \\
\hline $\begin{array}{c}\text { Primary care per } \\
\text { population }\end{array}$ & 4.06 & 2.49 & 4.08 & 2.51 & 4.24 & 2.57 & 4.28 & 2.59 & 4.32 & 2.67 \\
\hline Specialists per population & 6.40 & 10.31 & 6.73 & 10.43 & 6.94 & 10.56 & 7.10 & 10.66 & 7.27 & 10.77 \\
\hline Age-adjusted mortality & 92.07 & 15.11 & 91.46 & 16.11 & 90.79 & 16.09 & 91.45 & 15.46 & 90.58 & 15.33 \\
\hline Heart mortality & 21.07 & 8.19 & 20.96 & 8.26 & 20.90 & 8.32 & 21.26 & 8.30 & 20.82 & 8.19 \\
\hline Cancer mortality & 23.25 & 6.08 & 23.12 & 6.17 & 23.04 & 6.27 & 23.03 & 6.16 & 22.54 & 6.10 \\
\hline Per capita income & 19,106 & 4,510 & 19,678 & 4,661 & 21,161 & 5,099 & 22,132 & 5,470 & 22,132 & 5,470 \\
\hline $\begin{array}{l}\text { Percent high school } \\
\text { education }\end{array}$ & 69.55 & 10.34 & 69.55 & 10.34 & 69.55 & 10.34 & 69.55 & 10.34 & 69.55 & 10.34 \\
\hline Unemployment rate & 6.01 & 3.14 & 5.59 & 2.99 & 5.26 & 2.87 & 4.97 & 2.74 & 4.74 & 2.57 \\
\hline Percent elderly & 14.84 & 4.19 & 14.72 & 4.16 & 14.78 & 4.18 & 14.72 & 4.17 & 14.72 & 4.17 \\
\hline $\begin{array}{c}\text { Percent African } \\
\text { American }\end{array}$ & 9.06 & 14.87 & 9.17 & 14.95 & 9.26 & 15.05 & 9.36 & 15.14 & 8.63 & 14.34 \\
\hline Percent in poverty & 14.86 & 6.18 & 14.86 & 6.18 & 14.55 & 5.81 & 14.55 & 5.81 & 14.55 & 5.81 \\
\hline Percent in MSA & 27.00 & 44.40 & 27.00 & 44.40 & 27.00 & 44.40 & 27.00 & 44.40 & 27.00 & 44.40 \\
\hline
\end{tabular}

Source: Area Resource File (2002).

The implications of these all-county results, for both the earlier study and this analysis, would provide data supporting conflicting conclusions for the nation were the overall association of physician supply and mortality uniformly distributed across counties. However, there are strong regional patterns that are apparent from visual inspection of county or county cluster maps of mortality rates such as those presented in the Atlas of United States Mortality

Table 2: Relationship between Primary Care and Specialty Physician Ratios and Mortality Rates: Regression Coefficients, Standard Errors, and Statistical Significance, 1996-2000; U.S. Counties in 49 States

\begin{tabular}{|c|c|c|c|c|c|c|c|c|}
\hline \multirow{3}{*}{$\begin{array}{c}\text { Mortality } \\
\text { Measure } \\
\text { (per 10,000) }\end{array}$} & \multicolumn{4}{|c|}{ Primary Care } & \multicolumn{4}{|c|}{ Specialist } \\
\hline & \multicolumn{2}{|c|}{ Unadjusted } & \multicolumn{2}{|c|}{ Adjusted } & \multicolumn{2}{|c|}{ Unadjusted } & \multicolumn{2}{|c|}{ Adjusted } \\
\hline & Coefficient & $S E$ & Coefficient & $S E$ & Coefficient & $S E$ & Coefficient & $S E$ \\
\hline All cause & $0.2333^{* * *}$ & 0.0939 & $0.4098^{* * * * * * *}$ & 0.0788 & $-0.4507^{\text {******* }}$ & 0.0554 & -0.0028 & 0.0437 \\
\hline Heart & $-0.1883^{* * * * * *}$ & 0.0279 & $-0.0583^{* * *}$ & 0.0288 & $-0.0914^{* * * * * * *}$ & 0.0136 & -0.0017 & 0.0154 \\
\hline Cancer & $-0.0498^{* *}$ & 0.0201 & 0.0194 & 0.0207 & -0.0032 & 0.0090 & $0.0215^{\text {*** }}$ & 0.0104 \\
\hline
\end{tabular}

Note: $* * p<.05 ; * * * * *<<.001$.

Source: National Center for Health Workforce Analysis, BHPr, HRSA, 1998-2002 Area Resource Files. National Center for Health Statistics, CDC.

Compressed Mortality Files for 1996-2000. 
(Pickle et al. 1996). We sought to determine if these patterns would affect the relationship between physician supply and mortality using analyses that took into consideration regional geography.

\section{GWR}

The Starfield et al. article presented the results of 12 models in order to combine variations in cause of death (all-cause, cancer, and heart mortality rates), types of practitioners (primary care and specialist), and whether mortality rates were adjusted or unadjusted for age and gender. We estimate all 12 models in the same fashion as well using the GWR. Because our specific approach generates a separate coefficient for each county, resulting in 3,070 estimates for each of the models, we report only the distributions of the coefficient on the physician supply variables. The results are easiest to interpret when presented cartographically. For brevity, we present only three maps; complete results are available from the authors.

The general approach of GWR is to select a subsample of observations (here counties) for each of a series of spatial reference points. Our subsample of observations are counties that are "close" to the reference county. The goal is to generate a locally relevant correlation analysis. The general approach is as follows: Select a county, then determine the distance from that county centroid to every other county centroid in the study sample, placing less weight on more distal counties. For each model, perform the weighted regression, setting aside the estimated coefficient, and standard error on the provider supply variable. This process is repeated for all counties. We use county centroids included in the $\mathrm{ARF}$ as the spatial reference points, although other approaches are possible. Following the earlier report, we eliminate the District of Columbia from the sample. We also eliminate the four Hawaii counties as there are no counties that are "close" other than the other three in the state. This yields 3,070 counties in the study sample. Finally, we estimate the GWR version of the 12 models (adjusted and unadjusted; primary care and specialty; all-cause, heart, and cancer) both using the mixed/random effect model specification used by Starfield et al. and using the fixed effect specification outlined above. Thus, we obtain 3,070 estimates for each of the 12 models and two specifications. We first discuss the results for the random effects models, then turn to the fixed effects models.

\section{Mixed/Random Effects Models Using GWR}

We perform a spatial regression for a baseline regression similar to the PROC MIXED model reported earlier-using age-adjusted mortality as the 
dependent variable. Figure 1 presents estimates of the effect of primary care physician supply on age-adjusted mortality, unadjusted for other covariates. Shading denotes the magnitude of the association between primary care supply and mortality, with darker shading implying that counties with greater physician supply have lower mortality. The areas with a patterned overlay denote areas where the overall regressions reached statistical significance, which was set at a $p \leq .05$.

Strong regional patterns emerge from the use of the GWR approach. Primary care physicians are associated with decreased mortality on the east coast and upper Mississippi valley, but that correlation disappears in the west (with the exception of Washington State) and south central states. These patterns suggest that the relationship between physician supply, both specialist and primary care, is more complex than the relative ratio of specialists to primary care physicians or their absolute number. There appears to be strong regional patterns of mortality differences with rate ratios approaching 3; as well as differing patterns of association with physician supply that are spatially clustered. Figure 2 demonstrates the spatial relationship between mortality and primary supply adjusted for covariates. The strong negative (physicians decrease mortality) relationship disappears and a more regional relationship holds-primary care physicians are associated with lower mortality in and around Iowa and Wisconsin, while primary care supply is associated with higher mortality in Florida, Utah, and other Southern states.

\section{Fixed Effect GWR Models}

We extend the analysis using "fixed effect" models, allowing the countyspecific time-invariant unobserved component to be correlated with observed covariates. In general, these models find much weaker relationships between physician supply and mortality rates, with some small area exceptions. One sample map is shown in Figure 3 which shows the relationship between specialty supply and heart mortality. In some regions, such as western Missouri and eastern Kansas and Nebraska, more specialist supply is associated with lower mortality due to heart disease.

\section{DISCUSSION}

There are apparent and surprisingly large geographic differences in the mortality rates of the U.S. population. These variations have been persistent and are closely associated with racial, ethnic, and economic characteristics of the 


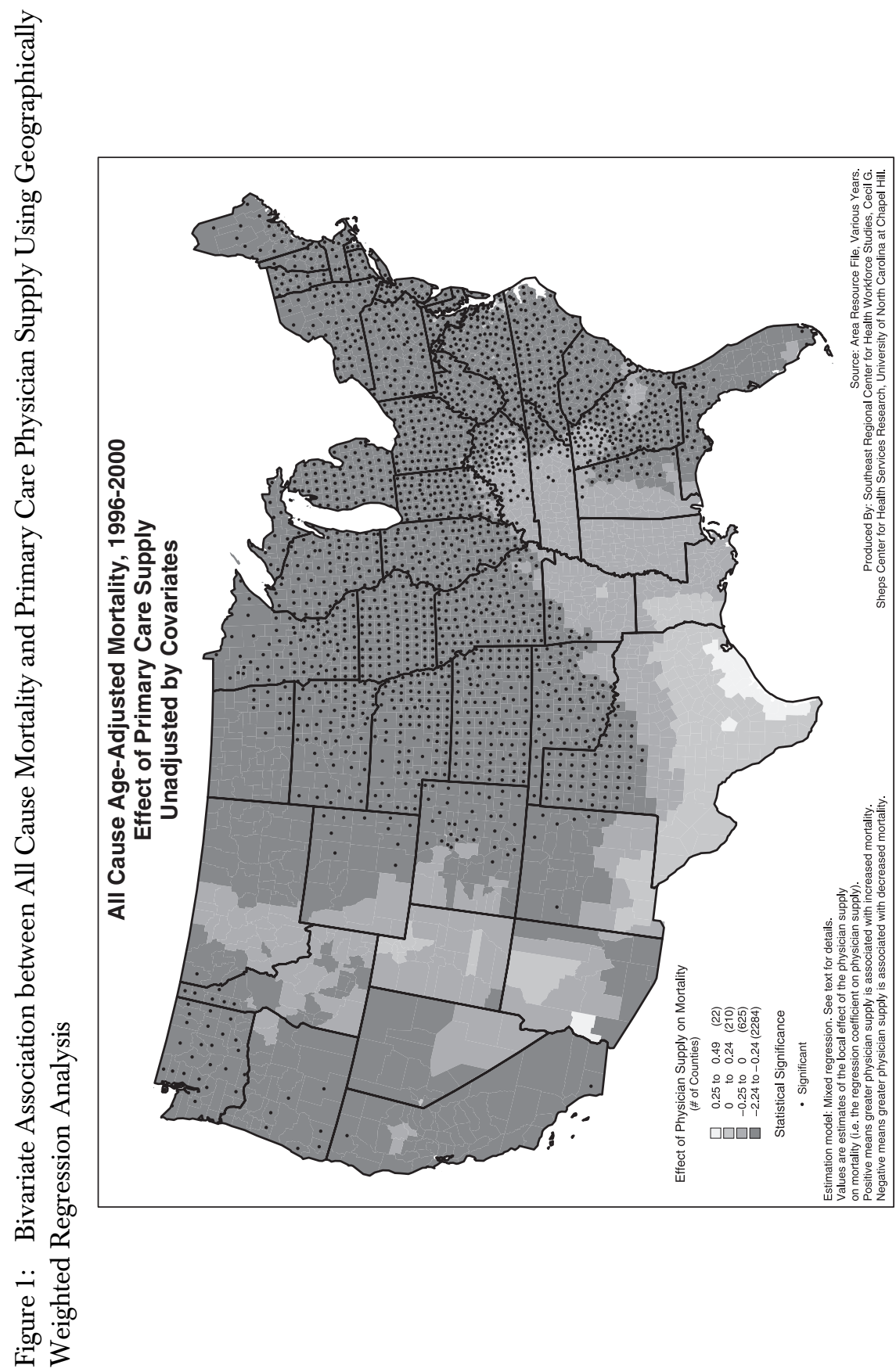


2244 HSR: Health Services Research 42:6, Part I (December 2007)

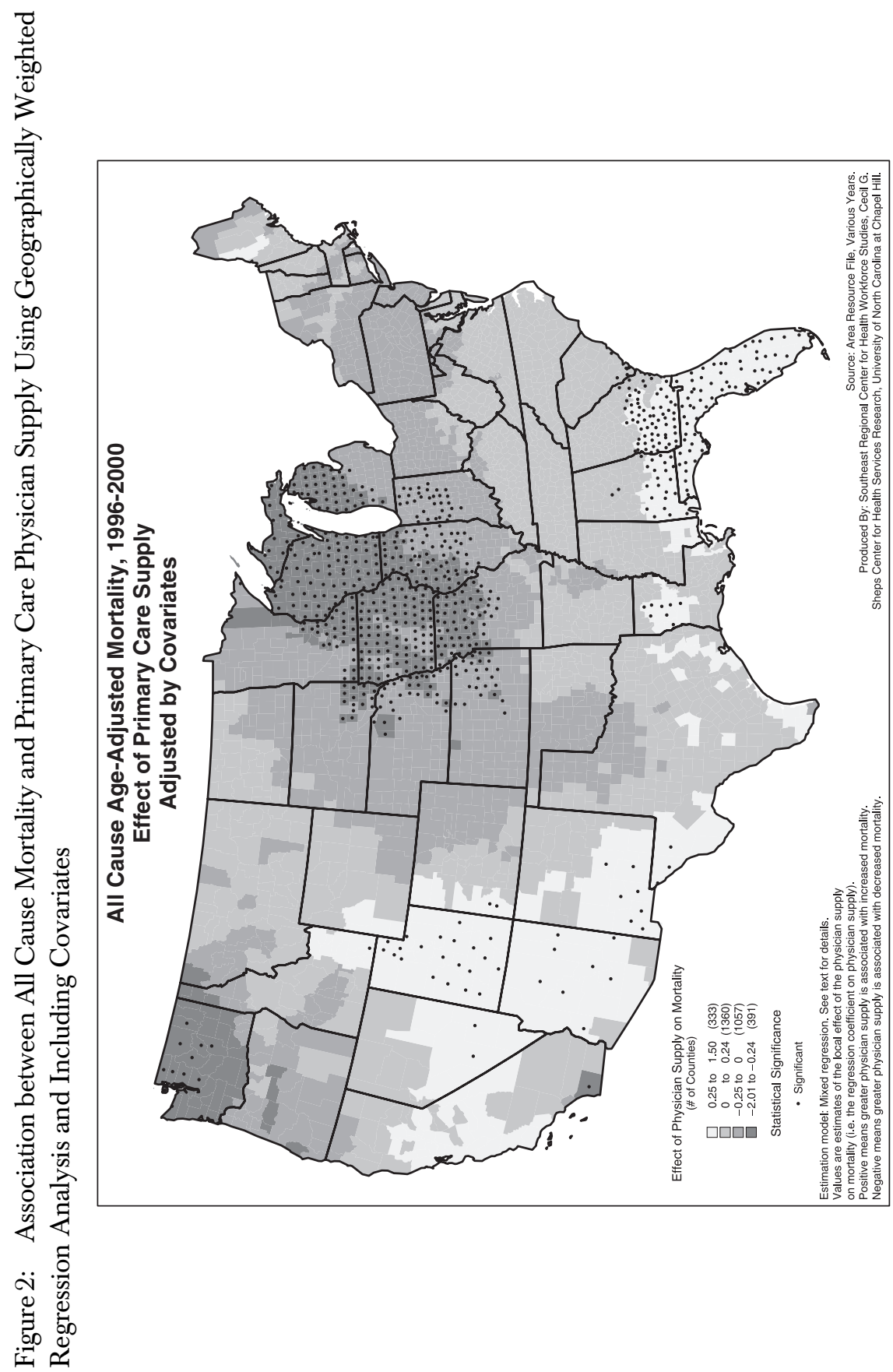




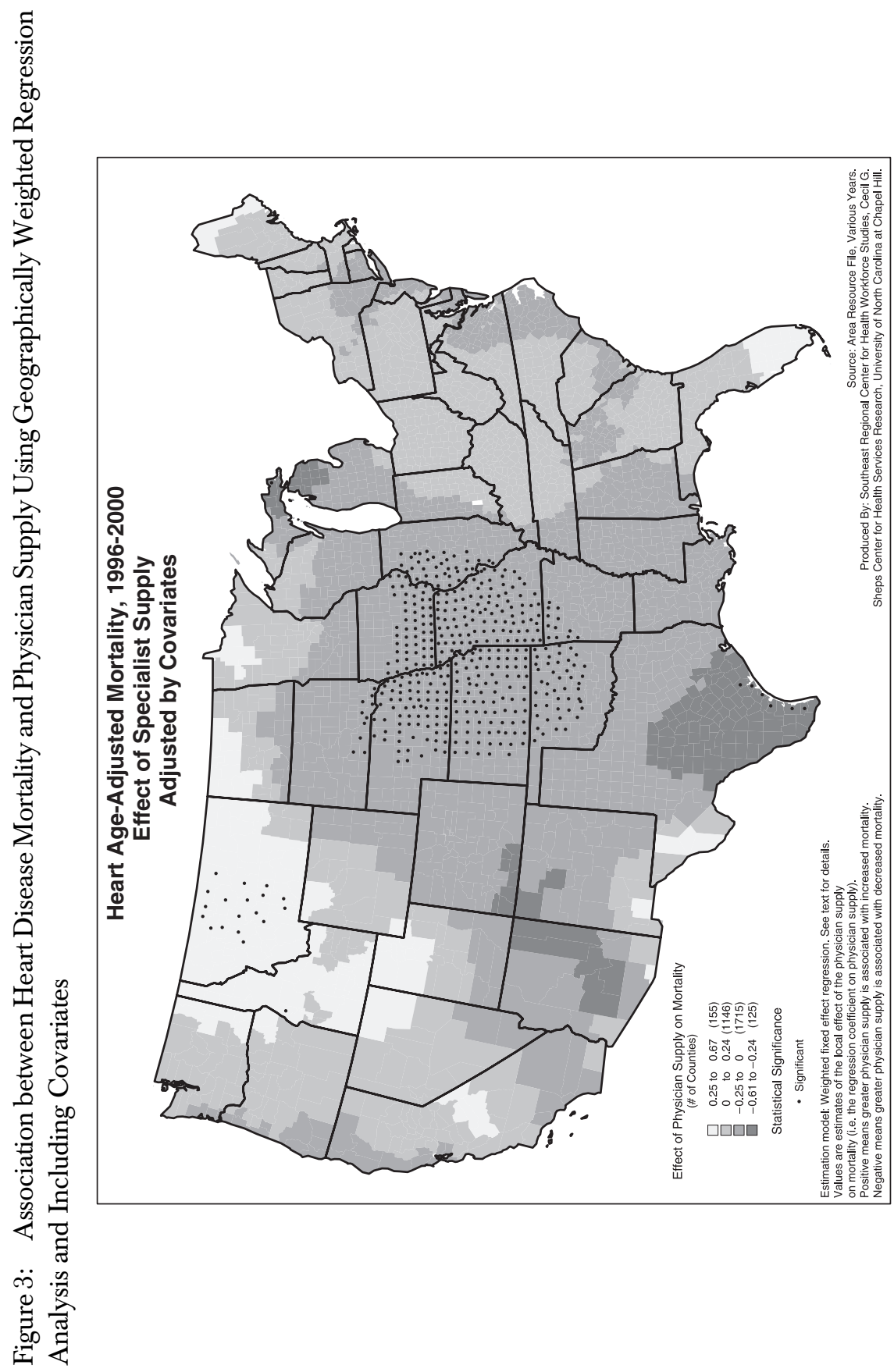


regions. There are similar differences in the distribution of physicians, but their distribution is not clearly related to mortality patterns. This study attempted to test the hypothesis that local, county-level physician supply, either of specialists or of primary physicians, was systematically associated with differences in mortality. We find evidence that such relationships do exist, holding constant population characteristics that reflect the influence of social and economic characteristics. However, these relationships are not consistent across the United States, there are regions where there are stronger and weaker associations between type of practitioner and mortality and other regions where no association is apparent. These patterns are sufficiently clustered in geographic regions to provoke further inquiry into their cause or, at least, their correlates.

\section{Strengths and Weaknesses of the Study}

This type of analysis is, in itself fraught with many technical problems, not the least of which are understanding what exactly are the dimensions of the concepts on which we focus. While mortality rates are relatively standard and well understood, the counting of physicians does not enjoy the same level of precision (Grumbach et al. 1995; Hart et al. 1997; Ricketts, Hart, and Pirani 2000). The measurement of primary care supply using secondary data sets is not standardized. The most common general definitions of primary care physicians include general and family practitioners, general pediatricians, general internists, and obstetricians-gynecologists with the last specialty group excluded in some definitions. Neither this nor the Starfield et al. analysis included nurse practitioners and physician assistants, who are also important providers of primary care (Cooper, Henderson, and Dietrich 1998). The definition of primary care included in the ARF follows that of the American Medical Association and their reports based on the Physician Masterfile. That definition, in general, follows the most common practices but includes a number of subspecialties within family medicine (such as geriatric medicine and sports medicine) as well as selected subspecialties in internal medicine, and obstetrics-gynecology, and pediatrics (Smart 2006). However, variations in the construction of a primary care physician supply number using even the $\mathrm{ARF}$, which includes an explicit primary care category for physicians can occur if other specified specialties identified in the file are included or excluded. This lack of direct comparability is likely common among similar studies where the definition of a type of physician depends on many separate variables and where the specific sources of physician supply data may vary according to the release date of the data set. 
This analysis attempted to replicate another published study of the relationship between mortality and physician supply and did so with surprisingly different results (Starfield, Shi, and Macinko 2005). These differences may have emerged because of misspecification of variables, a variation in the statistical analysis or because of the very clustered geographic patterns that appear to exist.

It is not clear how the overall supply of all specialists might affect cancer or cardiovascular mortality; future analysis of these disease-specific mortality rates should focus on groups of specialists who specifically treat these diseases.

The logic of a primary care-dominated system is self-evident to many and enjoys strong political as well as policy support in many countries. However, the United States has steadfastly resisted dominance, even coordination of its health care via primary care structures or practitioners. Some even speak of the potential demise of primary care (Sandy and Schroeder 2004), while others continue to see it as the best way to improve the nation's health indicators and bring greater equity to our system (Starfield, Shi, and Macinko 2005). The use of spatial variations in mortality rates to assess the relative contribution of practitioners of one type or another may be hazardous due to the very many and complex contributors to health outcomes, especially mortality. The assumption of such an analysis is that the primary contribution of practitioners is for the extension of life. Quoting Young (2005): "The role of health care does not lie exclusively in reducing mortality, but also in relieving pain and suffering, preventing disability, and improving quality of life, measures of health that are much less amenable to historical trend analysis than mortality"; this point of view suggests that physicians and other practitioners may find themselves working in places with mortality rates that are higher or lower for reasons other than their caregiving skills and their contribution to the population is focused on managing the quality of life of people. This statement should be considered when discussing the relative contribution of practitioners of all types to the health of populations. Suggesting that the relative value of one type of practitioner is less or greater than of another based on marginal differences in correlations with mortality rates perhaps drives the interpretation of data too far. Policy makers should take care before favoring programs that focus exclusively on primary care physician supply.

The fact that there are apparent regional patterns suggests that the direction for further analysis lies in the understanding of the geographic differences in the relationship between primary care or specialist supply and mortality. There needs to be further standardization of the measurement of 
primary care supply and the structure of local care delivery systems in order to understand what does improve health outcomes. Likewise, there may also be a need to better measure mortality or to adapt mortality rates to assess the performance of the health care system.

\section{ACKNOWLEDGMENTS}

This research was partially supported by Grant Number U79HP00035 from the Bureau of Health Professions, Health Resources and Services Administration, U.S. Department of Health and Human Services. The authors wish to thank Barbara Starfield, Ph.D., and Leiyu Shi, Ph.D., for their colleagueship and comments during the preparation of this article. We are grateful for the constructive comments and suggestions from the reviewers and editors.

Disclosures: No conflicts to disclose.

Disclaimers: This work does not represent the policy or opinions of the Bureau of Health Professions, the Health Resources and Services Administration, or the U.S. Department of Health and Human Services.

\section{NOTES}

1. A detailed description of our data analysis, including variable definitions, is available upon request.

2. In communications with the team at Johns Hopkins (personal communication with L. Shi, January 11, 2007), they indicated that the final analysis used the Generalized Estimations Equation (GEE) method in the $\mathrm{SAS}^{\mathbb{B}}$ system rather than PROC MIXED, which would be equivalent to the Stata ${ }^{B}$ approach reported here.

3. This term has some ambiguity due to its different use across disciplines. Here, we use the econometric interpretation of "fixed effects model." See, for example, Wooldridge (2002). This model is sometimes also known as the Least Squares Dependent Variable model. See Macinko, Starfield, and Shi (2003, p. 844) for more discussion.

4. The radius length was determined by cross-validation. See, for example Fotheringham, Brunsdon, and Charlton (2002).

5. The Johns Hopkins team indicated (personal communication with L. Shi, January $11,2007)$ that the specific variable was not formally age-adjusted but their use of percent elderly in the regression model indirectly adjusted for age. We have shared the manuscript and other results with the authors of the other work and continue discussions over analysis strategies to assess the effects of primary care on mortality and morbidity. 


\section{REFERENCES}

Bureau of Health Professions. 2002. Area Resource Files. Rockville, MD: Health Resources and Services Administration.

Cooper, R. A., T. Henderson, and C. L. Dietrich. 1998. "Roles of Nonphysician Clinicians as Autonomous Providers of Patient Care." Journal of the American Medical Association 280 (9): 795-802.

Cossman, R. E., J. S. Cossman, R. Jackson, and A. Cosby. 2003. "Mapping High or Low Mortality Places across Time in the United States: A Research Note on a Health Visualization and Analysis Project." Health Place 9 (4): 361-9.

Fisher, E. S., and J. E. Wennberg. 2003. "Health Care Quality, Geographic Variations, and the Challenge of Supply-Sensitive Care." Perspectives in Biology and Medicine 46 (1): 69-79.

Forrest, C. B., and B. Starfield. 1996. "The Effect of First-Contact Care with Primary Care Clinicians on Ambulatory Health Care Expenditures." Journal of Family Practice 43: 40-8.

Fotheringham, A. S., C. Brunsdon, and M. Charlton. 2002. Geographically Weighted Regression: The Analysis of Spatially Varying Relationships. Chichester, UK: Wiley.

Glance, L. G., A. Dick, T. M. Osler, Y. Li, and D. B. Mukamel. 2006. "Impact of Changing the Statistical Methodology on Hospital and Surgeon Ranking: The Case of the New York State Cardiac Surgery Report Card.” Medical Care 44 (4): 311-9.

Goodman, D. C., E. S. Fisher, T. A. Bubolz, J. E. Mohr, J. F. Poage, and J. E. Wennberg. 1996. "Benchmarking the US Physician Workforce." Journal of the American Medical Association 276 (22): 1811-7.

Goodman, D. C., S. S. Mick, D. Bott, T. Stukel, C. H. Chang, N. Marth, J. Poage, and H. J. Carretta. 2003. "Primary Care Service Areas: A New Tool for the Evaluation of Primary Care Services." Health Services Research 38 (1, part 1): 287-309.

Grumbach, K., S. H. Becker, E. H. Osborn, and A. B. Bindman. 1995. "The Challenge of Defining and Counting Generalist Physicians: An Analysis of Physician Masterfile Data." American Journal of Public Health 85 (10): 1402-7.

Hart, L. G., E. Wagner, S. Pirzada, A. F. Nelson, and R. A. Rosenblatt. 1997. "Physician Staffing Ratios in Staff-Model HMOs: A Cautionary Tale." Health Affairs (Millwood) 16 (1): 55-70.

Hausman, J., and D. McFadden. 1984. "Specification Tests in Econometrics." Econometrica 52: 1219-40.

James, W. L., R. E. Cossman, J. S. Cossman, C. Campbell, and T. Blanchard. 2004. "A Brief Visual Primer for the Mapping of Mortality Trend Data." International Journal of Health Geographics 3 (1): 7.

Kindig, D.A. 1997. Purchasing Population Health: Paying for Results. Ann Arbor, MI: University of Michigan Press.

Kindig, D. A., C. L. Seplaki, and D. L. Libby. 2002. "Death Rate Variation in US Subpopulations." Bulletin of the World Health Organization 80 (1): 9-15. 
Macinko, J., B. Starfield, and L. Shi. 2003. "The Contribution of Primary Care Systems to Health Outcomes within Organization for Economic Cooperation and Development (OECD) Countries, 1970-1998." Health Services Research 38(3): 831-65.

McKeown, T. 1979. The Role of Medicine: Dream, Mirage or Nemesis. Oxford: Blackwell. McKinlay, J. B., and S. M. McKinlay. 1977. "The Questionable Effect of Medical Measures on the Decline in Mortality in the United States in the Twentieth Century." Milbank Quarterly 55: 405-28.

Pickle, L. W., M. Mungiole, G. K. Jones, and A. A. White. 1996. Atlas of United States Mortality. Hyattsville, MD: U.S. Department of Health and Human Services.

Ricketts, T. C., L. G. Hart, and M. Pirani. 2000. "How Many Rural Physicians Are There?" Journal of Rural Health 16 (3): 198-207.

Sandy, L., and S. Schroeder. 2004. "Primary Care in a New Era, Disillusion and Dissolution?" In The Future of Primary Care, edited by J. Showstack, A. A. Rothman, and S. B. Hassmiller, pp. 161-79. San Francisco: Jossey-Bass.

Shi, L. 1992. "The Relationship between Primary Care and Life Chances." Journal of Health Care for the Poor and Underserved 3 (2): 321-35.

. 1994. "Primary Care, Specialty Care, and Life Chances." International Journal of Health Services 24 (3): 431-58.

Shi, L., J. Macinko, B. Starfield, R. Politzer, J. Wulu, and J. Xo. 2005. "Primary Care." American Journal of Public Health 95 (4): 674-80.

Shi, L., J. Macinko, B. Starfield, J. Wulu, J. Regan, and R. Politzer. 2003a. "The Relationship between Primary Care, Income Inequality, and Mortality in US States, 1980-1995." Journal of the American Board of Family Practice 16 (5): 412-22.

Shi, L., J. Macinko, B. Starfield, J. Xu, and R. Politzer. 2003b. "Primary Care, Income Inequality, and Stroke Mortality in the United States: A Longitudinal Analysis." Stroke 34 (8): 1958-64.

Smart, D. 2006. Physician Characteristics and Distribution in the US, 2006 Edition. Chicago: American Medical Association.

Starfield, B., L. Shi, A. Grover, and J. Macinko. 2005. "The Effects of Specialist Supply on Populations' Health: Assessing the Evidence." Health Affairs Web Exclusive W5: 98-107.

Starfield, B., L. Shi, and J. Macinko. 2005. "Contribution of Primary Care to Health Systems and Health.” Milbank Quarterly 83 (3): 457-502.

Wennberg, J. E., E. S. Fisher, and J. S. Skinner. 2004. "Geography and the Debate over Medicare Reform." Health Affairs (Millwood) Web Exclusive (suppl): W96-114.

Wooldridge, J.M. 2002. Economic Analysis of Cross Section and Panel Data. Cambridge, MA: MIT Press.

Young, F.W. 2001. "An Explanation of the Persistent Doctor-Mortality Association." Journal of Epidemiology and Community Health 55 (2): 80-4.

Young, T.K. 2005. Population Health Concepts and Methods. New York: Oxford University Press. 


\section{SUPPLEMENTARY MATERIAL}

The following supplementary material for this article is available:

Appendix A. EXHIBIT 2: Relationship between Primary Care and Specialist Physician Ratios and Mortality: Regression Coefficients, Standard Errors, and Statistical Significance, 1996-2000

This material is available as part of the online article from: http:// www.blackwellsynergy.com/doi/abs/10.1111/j.1475-6773.2007.00728.x (this link will take you to the article abstract).

Please note: Blackwell Publishing is not responsible for the content or functionality of any supplementary materials supplied by the authors. Any queries (other than missing material) should be directed to the corresponding author for the article. 